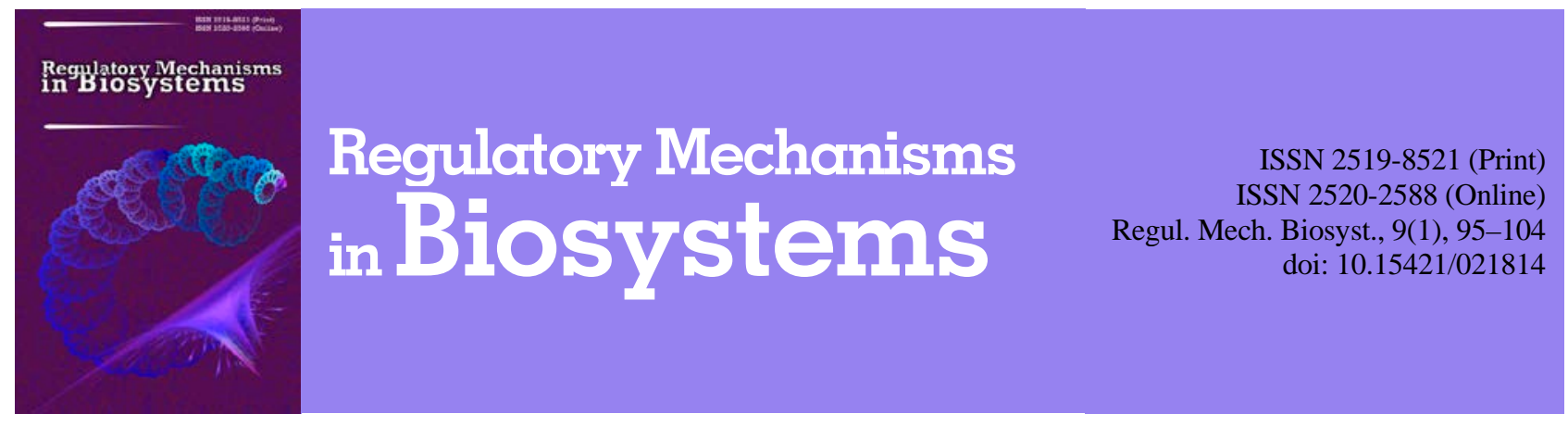

\title{
Prenatal morphogenesis \\ of compartments of the parenchyma of the lymph nodes of domestic cattle (Bos taurus)
}

\author{
P. N. Gavrilin, M. A. Lieshchova, O. G. Gavrilina, T. F. Boldyreva \\ Dnipro State Agrarian and Economic University, Dnipro, Ukraine
}

Article info

Received 12.01.2018

Received in revised form 14.02.2018

Accepted 15.02.2018

Dnipro State Agrarian and Economic University, Serhii Efremov st., 25 Dnipro, 49600, Ukraine Tel. +38-056-268-54-17. E-mail:

morphologagro@gmail.com, lieshchova.m.o@dsau.dp.ua

Gavrilin, P. N., Lieshchova, M. A., Gavrilina, O. G., \& Boldyreva, T. F. (2018). Prenatal morphogenesis of compartments of the parenchyma of the lymph nodes of domestic cattle (Bos taurus). Regulatory Mechanisms in Biosystems, 9(1), 95-104. doi: 10.15421/021814

The article analyzes the regularities of the formation and development of the lymphoid lobules of the parenchyma of the somatic (Limphonodi cervicales superficiales) and visceral (L. jejunales) lymph nodes in domestic cattle in the fetal period of ontogenesis. We used routine histological techniques and author's modification of the impregnation of total median sections with silver nitrate. Visualization of various zones of lymphoid lobules was carried out taking into account the specific for different cell zones architectonics of reticular fibers. It has been established that signs of morphological heterogeneity of parenchyma of lymph nodes are first found in three month-old fetuses, which is associated with the concentration of lymphoid tissue along the marginal sinus. Separation of lymphoid lobules and their structural and functional differentiation are first detected in five month fetuses. In the lymphoid lobules of five month-old fetuses all structural and functional cell zones are observable, among which the regions of clonal proliferation of $\mathrm{T}$ and $\mathrm{B}$ lymphocytes are the least developed, and regions of the transit corridors for lymphocytes migrating medullary and the cords (zone of potential accumulation of plasmocytes and antibody formation) are the most developed. Structural and functional transformations of compartments in the prenatal period of ontogenesis are accompanied by a predominantly moderate increase of the relative volume of specialized T- and B-dependent zones of lobules, against a background of a gradual decrease of the volume of transit corridors for lymphocytes migrating and zone of potential accumulation of plasmocytes and antibody formation. Due to the small volume and relatively low rates of development of the lymphocytes clonal proliferation zones, the quantitative ratios of the cellular zones in lymphoid lobules of the lymph nodes of domestic cattle in prenatal ontogenesis remain relatively stable, while maintaining the maximum indices of the development of transit corridors for lymphocytes migration and medullary cords. Among the zones of lymphocytes clonal proliferation throughout the fetal period, T-dependent zones predominate, the relative volume of which is 5.0-7.5 times greater than the volume of B-dependent zones. Lymphoid lobules in the lymph nodes of the domestic cattle fetuses of all age groups are arranged along the marginal sinus in one row and have a polar structure due to the formation of lymph nodes at one pole of the lobules in the interfollicular zone. In the visceral lymph nodes (L. jejunum) of 8-9 month-old fetuses, individual lymph nodes can form in paracortical strands, on the border with the interfollicular zone.

Keywords: lymphoid tissue; deep cortex units; interfollicular cortex; lymphatic nodules; lymphatic sinuses; paracortical and medullaru cords

\section{Пренатальный морфогенез компартментов паренхимы лимфатических узлов быка домашнего (Bos taurus)}

\author{
П. Н. Гаврилин, М. А. Лещева, Е. Г. Гаврилина, Т. Ф. Болдырева \\ Днипровский государственный аграрно-экономический университет, Днипро, Украина
}

Проанализированы закономерности формирования и развития субъединиц (лимфоидных долек) паренхимы соматических (Limphonodi cervicales superficiales) и висцеральных (L. jejunales) лимфатических узлов у быка домашнего в плодном периоде онтогенеза. Использовали рутинные гистологические методики и авторскую модификацию импрегнации тотальных срединных срезов азотнокислым серебром. Визуализацию различных зон лимфоидных долек осуществляли с учетом специфической для той или иной зоны архитектоники ретикулярных волокон. Признаки морфологической гетерогенности паренхимы лимфатических узлов впервые обнаружены у трехмесячных плодов, что связано с концентрацией лимфоидной ткани вдоль краевого синуса. Обособление лимфоидных долек и их структурно-функциональная дифференциация впервые выявляются у пятимесячных плодов. В лимфоидных дольках пятимесячных плодов различаются все структурно-функциональные зоны, среди которых наименее развитыми являются участки клональной пролиферации Т- и В-лимфоцитов, а наиболее - зона транзита лимфоцитов и 
мозговые тяжи. Структурно-функциональные преобразования компартментов в пренатальном периоде онтогенеза сопровождаются преимущественным умеренным увеличением объема специализированных Т- и В-зависимых зон долек, на фоне постепенного уменьшения объема зон транзита лимфоцитов и потенциальной аккумуляции плазмоцитов и антителообразования. Из-за незначительного объема и относительно низких темпов развития зон клональной пролиферации лимфоцитов, количественные соотношения клеточных зон в дольках лимфатических узлов быка домашнего в пренатальном онтогенезе остаются относительно стабильными, с сохранением максимальных показателей степени развития зон транзита и мозговых тяжей. Среди зон клональной пролиферации лимфоцитов на протяжении всего плодного периода преобладают Т-зависимые зоны, относительный объем которых в 5,0-7,5 раза превышает объем В-зависимых зон. Лимфоидные дольки в лимфатических узлах плодов быка домашнего всех возрастных групп располагаются в один ряд вдоль краевого синуса и имеют полярную структуру из-за формирования лимфатических узелков на одном полюсе долек в интерфолликулярной зоне. В висцеральных лимфатических узлах (тощей кишки) 8-9-месячных плодов отдельные лимфатические узелки могут формироваться в паракортикальных тяжах, на границе с интерфолликулярной зоной.

Ключевые слова: лимфоидная ткань; единицы глубокой коры; интерфолликулярная зона; лимфатические узелки; лимфатические синусы; паракортикальные и мозговые тяжи

\section{Введение}

На сегодня очевидным является тот факт, что паренхима лимфатических узлов млекопитающих имеет не слоистую, а дольчатую (компартментную) структуру (Kelly et al., 1975; Konenkov et al., 2008; Butler et al., 2016; Gavtilin et al., 2017a). Лимфоидные дольки в лимфатических узлах разных видов животных устроены по единому принципу и представлены четырьмя основными составляющими: зоны клональной пролиферации Т- и, соответственно, В-лимфоцитов; зона транзита лимфоцитов и межклеточного взаимодействия; зона аккумуляции плазмоцитов и синтеза антител (Kowala \& Schoefi, 1986; Margaris \& Black, 2012; Ikomi et al., 2012).

Зона транзита представляет собой биологический канал (транспортный коридор) для лимфоцитов, которые мигрируют через стенку вен с высоким эндотелием в паренхиму узлов (Ikomi et al., 2012; Ager, 2017). Данные структуры формируются вокруг соответствующих венозных сосудов (вен с высоким эндотелием), большая часть которых локализируется в интерфолликулярной зоне и паракортикальных тяжах (De Bruyn \& Cho, 1990; Platt \& Randolph, 2013; Ruddle, 2016). Интерфолликулярные зоны располагаются в непосредственной близости от главных коллекторов лимфы, которые в лимфатических узлах млекопитающих представлены двумя основными типами: лимфатическими пространствами между капсулой и паренхимой узлов (коллекторами I типа) и внутритрабекулярными лимфатическими цистернами (коллекторами II типа) (Gavrilin et al., 2017c). Зона акуммуляции плазмоцитов и синтеза антител в виде мозговых тяжей находится в лимфоидной дольке на противоположном полюсе от главных лимфатических коллекторов и граничит с терминальным участком внутриузлового лимфатического русла - воротным синусом (Von Andrian \& Mempel, 2003; Sixt et al., 2005; Konenkov et al., 2008; Olson et al., 2012; Houston et al., 2016).

Зона клональной пролиферации Т-лимфоцитов (центральные зоны единиц глубокой коры) находится между интерфолликулярной зоной и мозговыми тяжами. Т-зоны в лимфатических дольках являются единичными образованиями, формирующими основу каждого компартмента. Главной их структурно-функциональной особенностью является то, что они никогда непосредственно не контактируют с внутриузловыми лимфатическими пространствами, а миграция лимфоцитов из синусов в соответствующую зону происходит через каналы ретикулярного остова транзитных зон (Kaldjian et al., 2001; Katakai et al., 2004; Palm et al., 2016). Зоны клональной пролиферации В-лимфоцитов (лмфатические узелки), в отличие от соответствующих Т-зон, являются достаточно многочисленными, рассеянными диффузно (мозаично) в пределах каждой дольки и формируются исключительно вдоль внутриузловых лимфатических синусов (краевого, паракортикальных, иногда мозговых) (Katakai, 2004; Capece \& Kim, 2016; Nurken \& Marzhan, 2016; Gavrilin et al., 2017c).

В лимфатических узлах с коллекторами I типа, к которым также относятся соответствующие органы человека и лабораторных животных, большая часть лимфатических узелков формируется в интерфолликулярной зоне, в самом поверхностном слое паренхимы, вдоль краевого синуса (Rouse et al., 1984; Katakai, 2004; Ohtani \& Ohtani, 2008; Capece \& Kim, 2016; Iwasaki et al., 2016). В лимфатических узлах с коллекторами II типа узелки концентрируются в виде гнезд в глубоких участках паренхимы ближе к вершинам трабекул, где внутритрабекулярные синусы формируют расширения (Hoshi et al., 1986; Gavrilin et al., 2014; Gavrilin et al., 2017c). Тот или инной тип расположения лимфатических узелков в паренхиме узлов возможно связан с неравномерной концентрацией антигенпрезентирующих клеток во внутриузловых лимфатических пространствах, максимальное количество которых выявляется в лимфе внутриузловых лимфатических коллекторов, а минимальное - во второстепенных, более мелких, особенно мозговых и воротных синусов (Jia et al., 2012; Houston et al., 2016; Iwasaki et al., 2016).

Абсолютно доказанным, на сегодняшний день, является факт реактивного характера развития всех без исключения структурнофункциональных зон компартментов паренхимы лимфатических узлов. Указывается, что интенсивная антигенная стимуляция приводит к 3-5-кратному увеличению объема лимфатических долек и, соответственно, ее составляющих компонентов (Gretz et al., 1997; Sapin, 2006; Sainte-Marie, 2010). Установлено также, что в условиях естественной умеренной антигенной стимуляции объемные соотношения компонентов лимфатических долек в лимфатических узлах различных видов млекопитающих являются относительно стабильными. В соответствующих органах половозрельх животных максимальный объем характерен для зон клональной пролиферации Т-лимфоцитов (25-40\% совокупного объема паренхимы) и, несколько меньше, зон аккумуляции плазмоцитов и синтеза антител (20-30\%). При этом относительный объем зон транзита лимфоцитов в 2-3 раза (10-15\%), а зон клональной пролиферации В-лимфоцитов в 3-5 раз (5-15\%) меньше вышеуказанных зон компартментов с максимальной степенью развития (Nicander et al., 1991; Gavrilin et al., 2017c). Отмечается также, что в лимфатических узлах мозоленогих млекопитающих (верблюда одногорбого), с характерным многоуровневым типом расположения компартментов, зоны пролиферации обоих основных клонов лимфоцитов развиты в одинаковой степени (Gavrilin et al., 2017b).

Имеющиеся на сегодня сведения о закономерностях структуры долек в паренхиме лимфатических узлов млекопитающих в основном получены при исследовании данных органов в постнатальном периоде онтогенеза у половозрелых и физиологически зрелых особей в условиях «естественного» комплекса воздействия на органы иммунной системы антигенов как экзо-, так и эндогенного характера (Bélisle \& Sainte-Marie, 1981; Vyrenkov et al., 1995; Willard-Mack, 2006; Ikomi et al., 2012; Butler et al., 2016).

Формирование целостного представления о дискретной структуре паренхимы лимфатических узлов у млекопитающих невозможно без данных о развитии лимфатической дольки как основной структурно-функциональной единицы паренхимы узлов на всех этапах онтогенеза.

Антигенный гомеостаз как одно из ключевых условий сохранения биологической индивидуальности организма обеспечивается у млекопитающих комплексом различных механизмов резистентности и реактивности на всех этапах индивидуального развития, в том числе и в пренатальном онтогенезе (Hlystova, 1987; Sinkora et al., 2002; Jeklova et al., 2007; Ekman \& Iivanainen, 2009; Benezech et al., 2010). При этом структурно-функциональная состоятельность периферических лимфоидных органов у плодов млекопитающих формируется по данным ряда исследователей уже в плодном периоде онтогенеза, что особенно выражено у плодов 
зрелорождающих видов копытных животных, и характеризуется адекватной реакцией на антигены с формированием полноценного иммунного ответа (Nishikawa et al., 2003; Randall et al., 2008; Grigor'ev \& Moljanova, 2009).

Учитывая особый эпителио- и десмохориальный тип строения плаценты у болышинства видов копытных, которая в норме является абсолютно непроницаемой для макромолекул с потенциальными антигенными свойствами, основным фактором антигенной стимуляции паренхимы периферических лимфоидных органов являются антигены эндогенного происхождения, концентрация которых в организме плодов возрастает пропорционально степени развития соматических систем (Sapin et al., 1978; Aagaard et al., 2014; Parker \& Makori, 2017). Время появления признаков дефинитивного строения паренхимы лимфатических узлов у млекопитающих является дискуссионным. В работах разных авторов оно варьирует от средины плодного периода до начальных этапов постнатального онтогенеза (Sminia et al., 1986; Emelyanenko, 1987; Šinkora \& Butler, 2009; Grigor'ev \& Moljanova, 2009). При этом спектр исследуемых в лимфатических узлах плодов морфологических маркеров иммунокомпетентности в основном ограничивается такими показателями как общее количество лимфоидной паренхимы, признаки ее дифференцировки на корковое и мозговое вещество, наличие в паренхиме узлов лимфатических узелков (Grigor'ev \& Moljanova, 2009; Chuchkova et al., 2016).

Что касается аспектов формирования и морфогенеза лимфоидных долек в лимфатических узлах плодов, они на сегодняшний день исследованы недостаточно. Дольчатая структура паренхимы узлов обусловлена особенностями морфогенеза данных органов вследствие внедрения сразу нескольких мезенхимальных скоплений почек в просвете лимфатических синусов (Mebius, 2003). Однако дальнейшие механизмы морфогенеза и формирования зональной дольчатой структуры лимфоидной паренхимы в лимфатических узлах млекопитающих в условиях крайне ограниченного антигенного воздействия при автономном внутриутробном развитии в литературе практически не описаны. Прежде всего это относится к зрелорождающим видам копытных животных, у которых в силу высокой степени зрелости аппарата движения при рождении взаимодействие реактивных структур организма с факторами внешней среды нарастает лавинообразно с первых часов постнатального онтогенеза, что требует соответствующего уровня развития и компетентности антигенреактивных структур.

Цель данной статьи - определить особенности морфогенеза лимфоидных долек (компартментов) паренхимы в лимфатических узлах зрелорождающих видов млекопитающих с лимфатическими коллекторами простого типа на примере плодов быка домашнего на макро-микроскопическом и тканевом уровнях организации.

\section{Материал и методы исследований}

Материал для исследований отбирали от плодов быка домашнего (Bos taurus Linnaeus, 1758), полученных от беременных особей после убоя (по причинам, не связанным с инфекционными и инвазионными заболеваниями) в условиях мясоперерабатывающего предприятия «Юбилейный» города Днипро. Для исследований путем анатомического препарирования отбирали соматические - поверхностный шейный (Limphonodi cervicales superficiales) и висцеральные - тощей кишки (L. jejunales) лимфатические узлы от плодов разного возраста: 2-месячных $(\mathrm{n}=4), 3-(\mathrm{n}=5), 4-(\mathrm{n}=$ 10), 5- $(\mathrm{n}=12), 6$ - $(\mathrm{n}=5), 7$ - $(\mathrm{n}=7), 8-(\mathrm{n}=6)$ и 9-месячных $(\mathrm{n}=6)$ (Zelenevsky, 2013). Всего исследовано 110 органов. Возраст плодов определяли по массе, длине тела и степени развития производных кожи (Studencov, 2000).

Исследования проведены в Днипровском государственном аграрно-экономическом университете. Отобранные органы фиксировали в $10 \%$ растворе нейтрального формалина 5-10 суток. После фиксации целые органы или их серединные сегменты, полученные в плоскости, перпендикулярной их воротам, промывали под проточной водой в течение 6-12 часов для удаления формалина. Для получения обзорных гистологических препаратов часть органов и сегментов заливали в парафин, согласно общепринятым методикам, а часть использовали для получения тотальных срединных замороженных срезов с использованием микротома-криостата. Из парафиновых блоков на санном микротоме изготовляли серийные гистосрезы толщиной 5-8 мкм с дальнейшей окраской гематоксилином (Эрлиха) - эозином, азур II - эозином и пикрофуксином по Ван-Гизон. На микротоме-криостате МК-25М готовили тотальные срединные замороженные срезы лимфатических узлов с последующей импрегнацией их нитратом серебра по методике Фута в модификации Gavrilin (1999). Этот метод окраски использовали для определения особенностей структурных преобразований ретикулярной стромы органов и одновременной визуализации как лимфоидных долек, так и их отдельных зон.

Гистологические препараты исследовали с использованием световых микроскопов Olimpus CX-41 и Leica DM 1000 (окуляр ${ }^{\times} 10$, объективы $\left.{ }^{\times} 4,{ }^{\times} 10,{ }^{\times} 40\right)$. В гистологических препаратах, окрашенных гематоксилином и эозином, по Ван-Гизон, импрегнированных нитратом серебра, определяли качественные и количественные показатели степени развития и дифференцировки тканевых компонентов (стромы, паренхимы) и внутриорганных лимфатических синусов, а также особенности формирования лимфоидных долек и их отдельных функциональных зон: межклеточного взаимодействия и транзита - периферия единиц глубокой коры (паракортекса); клональной пролиферации Т-лимфоцитов - центр единиц глубокой коры (паракортекса); клональной пролиферации В-лимфоцитов - лимфатические узелки; накопления плазматических клеток и синтеза антител - мозговые тяжи). Количественный анализ тканевых компонентов стромы, лимфоидной паренхимы с ее структурными зонами и лимфатических синусов проводили методом «точечного счета» с использованием окулярных тестовых систем и нанесенными равноудаленными точками (100 точек) на всей площади гистопрепарата (Avtandilov, 1990). Относительный объем вышеуказанных компонентов и зон определяли по формуле:

$$
\mathrm{V}_{\mathrm{i}}=\mathrm{P}_{\mathrm{i}} / \mathrm{P}_{\mathrm{t}} \cdot 100 \% \text {, }
$$

где $\mathrm{V}_{\mathrm{i}}$ - относительный объем исследуемого компонента, $\mathrm{P}_{\mathrm{i}}$ - число точек, попавших на структурный компонент, $\mathrm{P}_{\mathrm{t}}-$ общее число точек тестовой системы, попавших на гистопрепарат.

Необходимое число точек для получения достоверных данных п̃ (минимальный размер выборки, при котором выборочные наблюдения отклоняются от значений для генеральной совокупности не болыше чем на 5\%), определяли по формуле:

$$
\tilde{\mathrm{n}}=400(100-\mathrm{n}) / \mathrm{n} \text {, }
$$

где $\mathrm{n}$ - число точек, приходящихся на анализируемый компонент при предварительном подсчете 100 точек (Avtandilov, 1990).

Микрофотографии получали с помощью микроскопа Leica DM1000 (окуляр ${ }^{\times} 4$, объективы ${ }^{\times} 10 / 0,25,{ }^{\times} 40 / 0,65$ ), интегрированного с персональным компьютером.

Статистический анализ результатов проведен в Statistica 10.0 (StatSoft Inc., USA). Различия между выборками определены с использованием ANOVA и считались значимыми при $\mathrm{P}<0,05$.

\section{Результаты}

Лимфатические узлы у быка домашнего до начала плодного периода представлены мезенхимальными тканевыми зачатками и отдельными группами клеток гематогенного происхождения (рис. 1).

Выраженная дифференцировка лимфатических узлов на строму и паренхиму определяется начиная только с 3-месячного возраста. С данного возраста и до конца пренатального периода онтогенеза, паренхима лимфатических узлов является наиболее развитым тканевым компонентом (табл. 1). У 3-месячных плодов паренхима лимфатических узлов представлена лимфоидной тканью, а соединительнотканная строма - плотной волокнистой неоформленной соединительной тканью с соответствующим клеточным составом и структурой межклеточного вещества. В данный период развития строма четко подразделяется на капсулу и воротное утолщение с многочисленными кровеносными и лимфатическими сосудами, но капсулярные трабекулы выражены незначительно (рис. 2). 


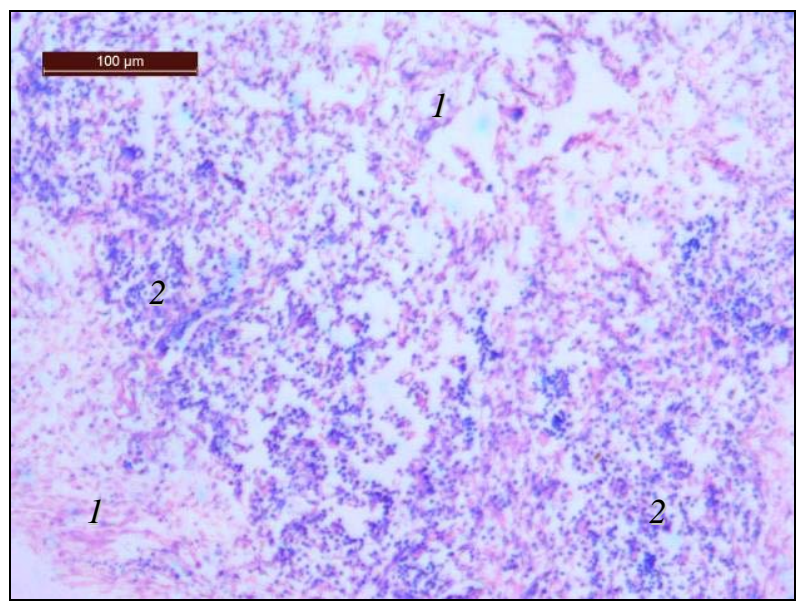

Рис. 1. Скопление мезенхимальных (1) и гематогенных (2) клеток в зачатке поверхностного шейного лимфатического узла: азур II и эозин

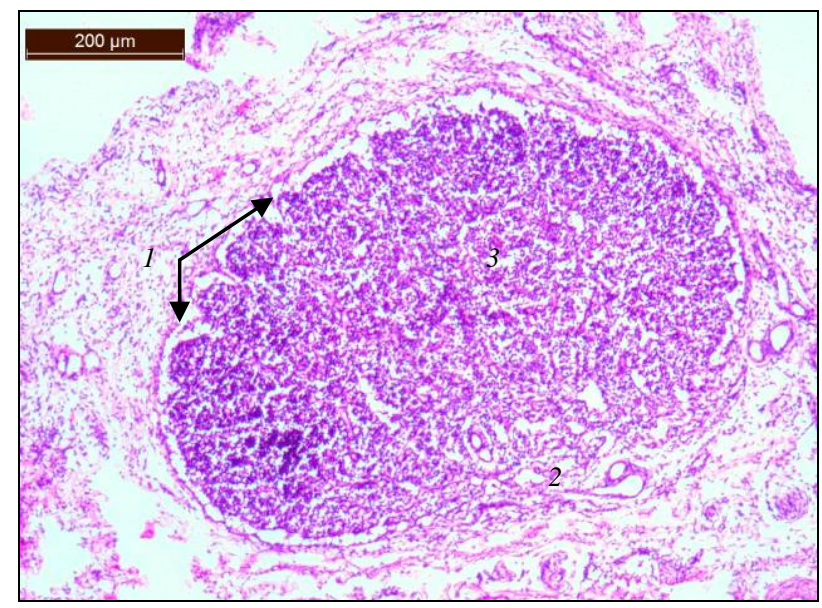

Рис. 2. Капсула (1), воротное утолщение (2), лимфоидная паренхима (3) лимфатического узла тощей кишки 3-месячного плода: гематоксилин и эозин

\section{Таблица 1}

Динамика относительного объема (\%) лимфоидной паренхимы и соединительнотканной стромы лимфатических узлов быка домашнего в пренатальном периоде онтогенеза (x \pm SD)

\begin{tabular}{llccccccc}
\hline \multirow{2}{*}{ Узел } & \multirow{2}{*}{ Тканевый компонент (\%) } & \multicolumn{7}{c}{ Bозраст, мес. } \\
\cline { 3 - 8 } & & & $3, \mathrm{n}=5$ & $4, \mathrm{n}=10$ & $5, \mathrm{n}=12$ & $6, \mathrm{n}=10$ & $7, \mathrm{n}=7$ & $8, \mathrm{n}=6$ \\
\hline Поверхностный & соединительнотканная строма & $9,90 \pm 1,52^{\mathrm{a}}$ & $13,3 \pm 2,92^{\mathrm{b}}$ & $14,56 \pm 2,48^{\mathrm{b}}$ & $14,92 \pm 2,45^{\mathrm{b}}$ & $16,24 \pm 1,49^{\mathrm{b}}$ & $17,18 \pm 0,97^{\mathrm{b}}$ & $17,28 \pm 1,06^{\mathrm{b}}$ \\
шейный & лимфоидная паренхима & $90,10 \pm 1,52^{\mathrm{c}}$ & $86,67 \pm 2,92^{\mathrm{d}}$ & $76,79 \pm 4,39^{\mathrm{e}}$ & $76,04 \pm 2,75^{\mathrm{e}}$ & $73,67 \pm 2,38^{\mathrm{e}}$ & $73,85 \pm 0,75^{\mathrm{e}}$ & $68,38 \pm 1,45^{\mathrm{f}}$ \\
Тощей кишки & соединительнотканная строма & $19,16 \pm 2,31^{\mathrm{g}}$ & $18,31 \pm 1,71^{\mathrm{g}}$ & $14,23 \pm 2,03^{\mathrm{h}}$ & $13,73 \pm 2,11^{\mathrm{h}}$ & $13,40 \pm 2,23^{\mathrm{h}}$ & $10,92 \pm 2,05^{\mathrm{h}}$ & $15,08 \pm 1,93^{\mathrm{i}}$ \\
& лимфоидная паренхима & $80,84 \pm 2,31^{\mathrm{j}}$ & $81,69 \pm 1,71^{\mathrm{j}}$ & $78,65 \pm 1,68^{\mathrm{k}}$ & $78,10 \pm 2,81^{\mathrm{k}}$ & $75,26 \pm 6,43^{\mathrm{k}}$ & $74,47 \pm 4,97^{\mathrm{k}}$ & $72,43 \pm 5,82^{\mathrm{k}}$ \\
\hline
\end{tabular}

Примечание: разными латинскими буквами обозначены выборки достоверно отличающиеся одна от другой $(\mathrm{P}<0,05)$ по результатам теста Тьюки.

Для лимфатических узлов плодов данного возраста характерно значительное развитие лимфоидной ткани, относительный объем которой, на фоне отсутствия четко выраженных синусов узлов, в 4-9 раз больше объема соединительнотканной стромы (табл. 1).

Начиная с третьего месяца пренатального развития плодов в лимфатических узлах наблюдается разделение лимфоидной паренхимы на две зоны: большую центральную (мозговое вещество) и меньшую периферическую (корковое вещество) (рис. 3а). Центральная зона имеет однородную структуру, менее плотную, ее ретикулярная основа представлена густой сетью извитых волокон, которые, объединяясь между собой, образуют равномерные ячейки средних размеров (рис. 3б). Периферическая зона густо заполнена малыми лимфоцитами, имеет вид тонкой полоски, размещенной вдоль капсулы. Сеть ретикулярных волокон в этой зоне более разрежена, а большинство волокон преимущественно ориентировано перпендикулярно капсуле.

Соединительнотканная строма в разных лимфатических узлах развита неравномерно. В поверхностном шейном лимфатическом узле относительный объем соединительнотканной стромы при этом минимальный, до 4-месячного возраста отмечено достоверное его увеличение и стабилизация до конца плодного периода. В лимфатическом узле тощей кишки относительный объем соединительнотканной стромы значительно выше, он максимален, затем наблюдается постепенное его уменьшение (начиная с 5-месячного возраста) и незначительное увеличение (к концу плодного периода). В первой трети плодного периода (2-4 месяца) относительная площадь лимфоидной паренхимы имеет максимальное значение, начиная с 4-месячного возраста в поверхностном шейном и 5-месячного в лимфатических узлах тощей кишки этот показатель постепенно снижается, достигая своего минимума у 9-месячних плодов. Динамика относительного объема лимфоидной паренхимы у плодов быка связана с процессами формирования системы лимфатических синусов, развитие которых сопровождается ее снижением на фоне выраженной морфологической сегрегации паренхимы узлов.

В 4-месячном возрасте наиболее значимо изменяется соединительнотканная строма.

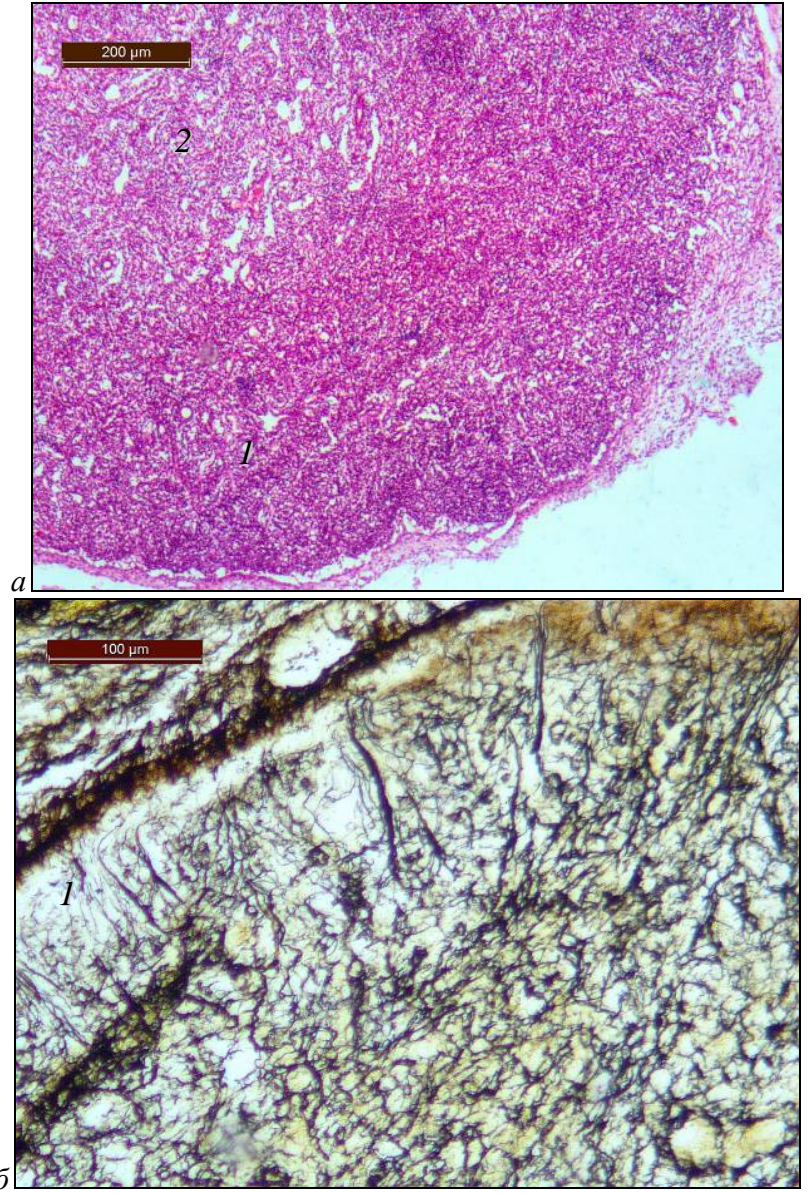

Рис. 3. Корковое (1) и мозговое (2) вещество паренхимы поверхностного шейного лимфатического узла 3-месячного плода: $a-$ гематоксилин и эозин, $\sigma$ - импрегнация азотнокислым серебром 
В поверхностных шейных узлах выявляется относительно неширокая соединительнотканная капсула с тонкими капсулярными трабекулами. В отличие от соматических, в висцеральных лимфатических узлах соединительнотканная капсула тоныше, капсулярные трабекулы менее выражены, воротное утолщение имеет небольшую площадь и овальную форму.

Как в соматических, так и в висцеральных лимфатических узлах 4-месячных плодов впервые выявляется подкапсулярный (краевой) синус (рис. 4а). Лимфоидная паренхима изменяется в менышей степени, но именно в это время впервые появляются признаки ее функциональной специализации. Периферическая зона лимфоидной паренхимы расширяется, плотность размещения в ней клеток увеличивается. Капсулярными трабекулами и промежуточными (корковыми) синусами паренхима начинает разделяться на отдельные дольки. Центральная зона лимфатических узлов существенно не изменяется, но отмечается начало формирования системы мозговых синусов и мозговых тяжей, с соответственной архитектоникой ретикулярных сетей (рис. 4б).

В лимфатических узлах 5-месячных плодов наиболее выраженные изменения характерны для лимфоидной паренхимы. Изза утолщения капсулярных трабекул и развития вокруг них промежуточных корковых синусов дольчатая структура паренхимы становится четко выраженной. В срединных срезах лимфатических узлов 5-месячных плодов лимфоидные дольки расположены в один слой и развиты относительно равномерно.

У плодов быка домашнего, как и у новорожденных особей данного вида и половозрелых лабораторных животных, лимфатические дольки паренхимы лимфатических узлов состоят из комплекса клеточных тяжей: периферические зоны единиц глубокой коры и интерфолликулярной зоны (транзита лимфоцитов и межклеточного взаимодействия), сферических структур - центры единиц глубокой коры и лимфатические узелки (клональной пролиферации лимфоцитов) и мозговых тяжей (зон потенциального накопления плазматических клеток и синтеза антител). В данный период практически в каждой лимфоидной дольке лимфатического узла определяются все функциональные зоны, но степень их развития значительно отличается как в пределах долек одного узла, так и долек соматических и висцеральных лимфатических узлов.

Наиболее развитыми зонами лимфатических долек паренхимы лимфатических узлов 5-месячных плодов являются единицы глубокой коры и мозговые тяжи, относительный объем которых практически одинаков как в соматических, так и в висцеральных лимфатических узлах (табл. 2).

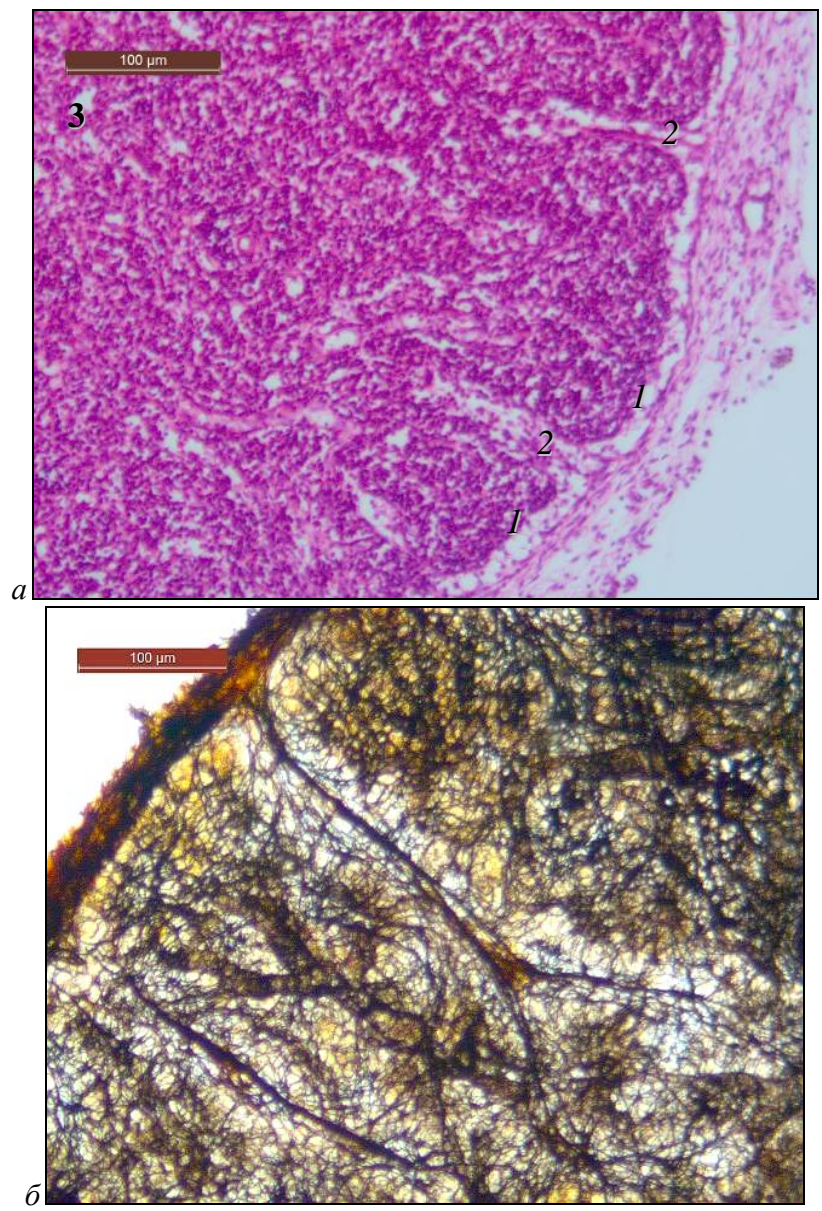

Рис. 4. Подкапсулярный (1), промежуточные (2), мозговые (3) лимфатические синусы в поверхностном шейном лимфатическом узле 4-месячного плода: $a$ - гематоксилин и эозин; б- импрегнация азотнокислым серебром

Таблица 2

Динамика относительного объема (\%) компонентов лимфоидной паренхимы лимфатических узлов быка домашнего в пренатальном периоде онтогенеза ( $\mathrm{x} \pm \mathrm{SD})$

\begin{tabular}{|c|c|c|c|c|c|c|}
\hline \multirow{2}{*}{ Узел } & \multirow{2}{*}{ Компоненты лимфоидной паренхимы } & \multicolumn{5}{|c|}{ Возраст, мес } \\
\hline & & $5, \mathrm{n}=12$ & $6, n=10$ & $7, \mathrm{n}=7$ & $8, \mathrm{n}=6$ & $9, \mathrm{n}=6$ \\
\hline \multirow{5}{*}{$\begin{array}{l}\text { Поверх- } \\
\text { ностный } \\
\text { шейный }\end{array}$} & интерфолликулярная зона & $4,83 \pm 2,47^{a}$ & $6,10 \pm 2,30^{\mathrm{a}}$ & $6,21 \pm 1,99^{\mathrm{a}}$ & $8,60 \pm 2,13^{\mathrm{a}}$ & $9,48 \pm 3,14^{\mathrm{a}}$ \\
\hline & центральные зоны единиц глубокой коры & $2,45 \pm 0,71^{\mathrm{b}}$ & $4,63 \pm 1,15^{\mathrm{c}}$ & $5,46 \pm 1,21^{\mathrm{c}}$ & $5,48 \pm 0,72^{\mathrm{c}}$ & $6,43 \pm 0,92^{c}$ \\
\hline & паракортикальные тяжи & $34,79 \pm 2,47^{d}$ & $35,85 \pm 2,31^{d}$ & $22,43 \pm 1,85^{\mathrm{e}}$ & $21,13 \pm 2,15^{\mathrm{e}}$ & $16,88 \pm 3,24^{f}$ \\
\hline & лимфатические узелки & $0,52 \pm 0,41^{\mathrm{g}}$ & $0,70 \pm 0,37^{\mathrm{g}}$ & $0,71 \pm 0,27^{\mathrm{g}}$ & $1,07 \pm 0,40^{\mathrm{g}}$ & $1,27 \pm 0,45^{\mathrm{g}}$ \\
\hline & мозговые тяжи & $34,21 \pm 4,12^{\mathrm{h}}$ & $29,10 \pm 4,37^{i}$ & $38,86 \pm 2,48^{j}$ & $37,58 \pm 2,61^{\mathrm{j}}$ & $34,33 \pm 3,82^{j}$ \\
\hline \multirow{5}{*}{$\begin{array}{l}\text { Тощей } \\
\text { кишки }\end{array}$} & интерфолликулярная зона & $6,40 \pm 1,28^{k}$ & $5,67 \pm 1,50^{k}$ & $7,33 \pm 1,45^{1}$ & $7,62 \pm 2,28$ & $9,90 \pm 2,19$ \\
\hline & центральные зоны единиц глубокой коры & $2,70 \pm 1,13^{\mathrm{m}}$ & $6,76 \pm 1,67^{\mathrm{m}}$ & $9,07 \pm 1,42^{n}$ & $10,41 \pm 1,51^{\mathrm{n}}$ & $11,82 \pm 1,88^{\mathrm{n}}$ \\
\hline & паракортикальные тяжи & $33,00 \pm 2,68^{\circ}$ & $23,20 \pm 3,97^{p}$ & $20,93 \pm 2,79^{p}$ & $22,53 \pm 2,90^{\mathrm{P}}$ & $25,12 \pm 3,32^{\mathrm{P}}$ \\
\hline & лимфатические узелки & $1,41 \pm 0,60^{q}$ & $1,75 \pm 0,43^{q}$ & $2,43 \pm 0,36^{\mathrm{r}}$ & $2,42 \pm 0,39^{r}$ & $3,10 \pm 0,47^{s}$ \\
\hline & мозговые тяжи & $35,14 \pm 2,63^{t}$ & $40,73 \pm 3,28^{u}$ & $35,50 \pm 7,29^{u}$ & $31,50 \pm 5,60^{\mathrm{u}}$ & $22,48 \pm 5,47^{v}$ \\
\hline
\end{tabular}

Примечание: см. табл. 1.

Единицы глубокой коры являются основой каждой лимфоидной дольки и имеют четкую полярную дифференциацию. Расширенный полюс непосредственно граничит с подкапсулярным синусом, а суженный направлен к воротному утолщению, боковые поверхности ограничены промежуточными корковыми синусами, расположенными преимущественно вдоль капсулярных трабекул. Каждая единица глубокой коры, начиная с 5-месячного возраста плодов, четко разделяется на периферическую и центральную зоны. Периферическая зона представлена паракортикальными тяжами и интерфолликулярной зоной (корковым плато). Максимальный относительный объем имеют паракортикальные тяжи, которые в 5-
7 раз превышают объем интерфолликулярной зоны (табл. 2). Наименее развитыми зонами лимфоидных долек являются зоны размножения Т- и В-лимфоцитов, при этом центры единиц глубокой коры, которые являются зонами клональной пролиферации Т-лимфоцитов, более развиты, нежели зоны пролиферации В-лимфоцитов (лимфатические узелки).

Лимфатические узелки в лимфатических узлах 5-месячных плодов выявляются в незначительном количестве и только первичные (без центров размножения), их относительный объем менее $1 \%$ в соматических и менее $2 \%$ - в висцеральных. Они преимущественно формируются на основе интерфолликулярной зоны 
и в этом возрасте локализируются вдоль краевого синуса. Во всех исследуемых лимфатических узлах плодов данного возраста лимфоидные дольки располагаются в один ряд, но развиты неравномерно в соматических и висцеральных лимфоузлах. В поверхностном шейном лимфатическом узле дольки четко разделены между собой хорошо развитыми капсулярными трабекулами, вдоль которых расположены промежуточные синусы (рис. 5а). В лимфоузлах тощей кишки из-за менее развитого трабекулярного аппарата и из-за незначительного просвета промежуточных синусов дольковая структура паренхимы выражена не четко (рис. 5б).

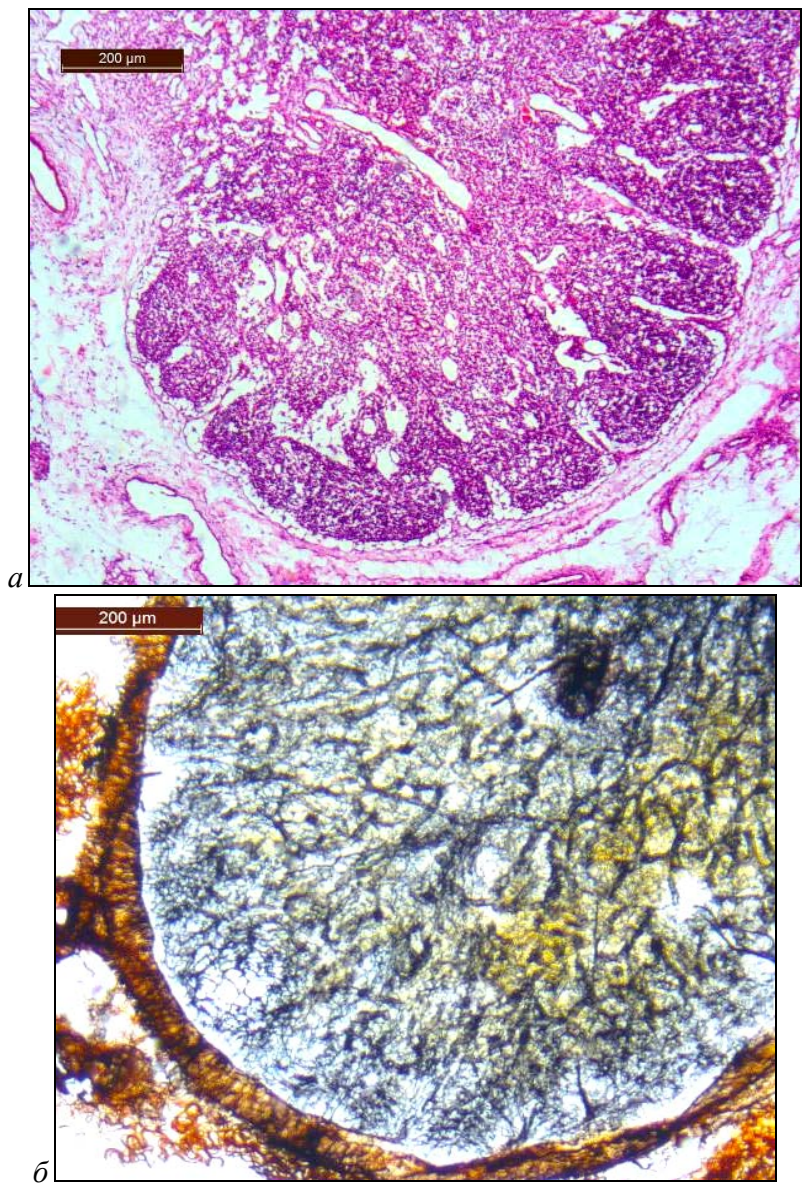

Рис. 5. Лимфоидные дольки лимфатических узлов 5-месячных плодов быка домашнего: $a-$ в поверхностном шейном

(гематоксилин и эозин), $б$ - в лимфатическом узле тощей кишки (импрегнация азотнокислым серебром)

При исследовании гистопрепаратов лимфатических узлов, импрегнированных азотнокислым серебром, определено, что для каждой функциональной зоны характерна специфическая архитектоника ретикулярных волокон. Для центральных зон единиц глубокой коры это крупнопетлистая сотообразная, для паракортикальных тяжей и итерфолликулярной зоны - мелкопетлистая со специфической плетенеподобной структурой (рис. 6а). Для лимфатических узелков характерна равномерная среднепетлистая сеть, а для мозговых тяжей - плотные мелкопетлистые сети, которые окружают кровеносные сосуды (рис. 6б).

Также начиная с 5-месячного возраста плодов значительного развития достигает система лимфатических синусов в лимфатических узлах, которая состоит из подкапсулярного (краевого), воротного, межуточных корковых и хорошо выраженных мозговых синусов (рис. 7).

Наиболее развитыми функциональными зонами лимфоидной паренхимы узлов быка домашнего на протяжении плодного периода остаются единицы глубокой коры и мозговые тяжи. В единицах глубокой коры большую часть объема занимают паракортикальные тяжи. Динамика их относительного объема в паренхиме поверхностного шейного узла характеризуется стабильностью этого показателя на протяжении 5-6-го месяца, достоверным снижением начиная с 7-месячного возраста плодов с достижением минимальных значений к концу плодного периода онтогенеза. В лимфатических узлах тощей кишки данный показатель достоверно снижается уже с 6-месячного возраста плодов, в последующем стабилизируется и до конца плодного периода не превышает 20 $25 \%$ (табл. 2).
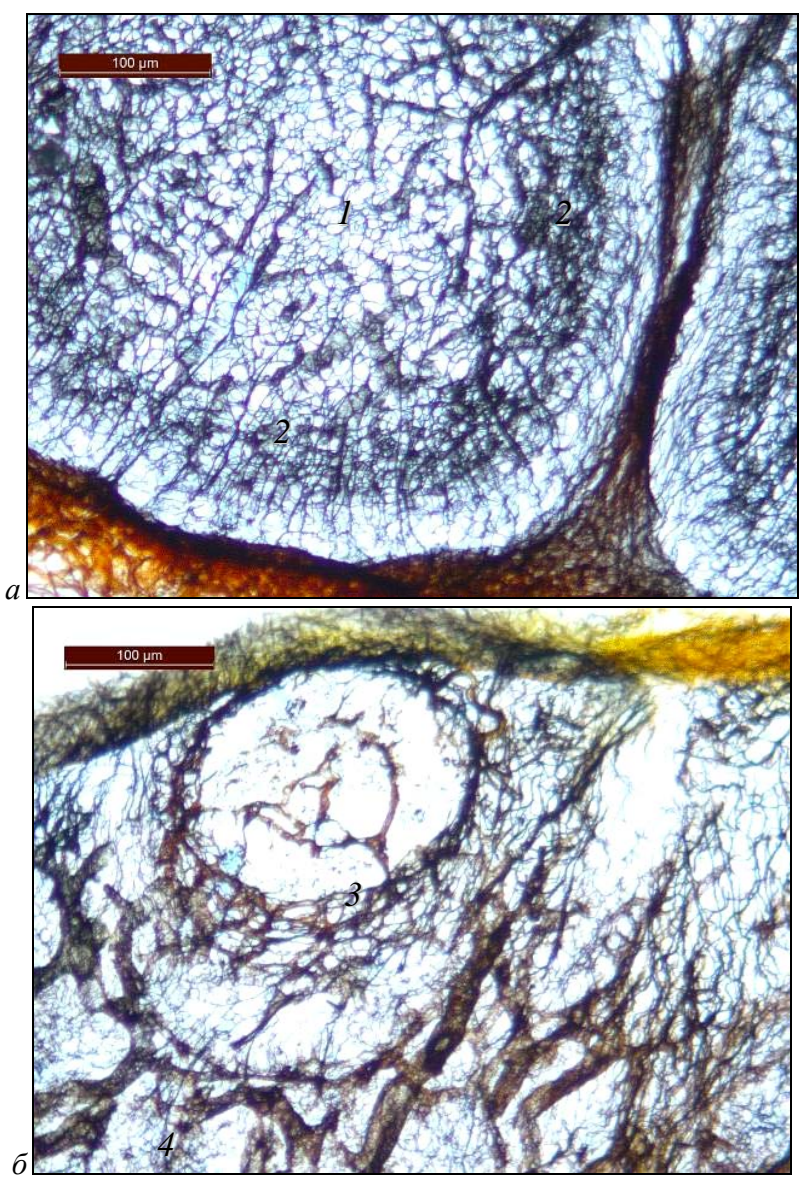

Рис. 6. Архитектоника ретикулярных волокон центра единицы глубокой коры (1), паракортикальных тяжей и интерфолликулярной зоны (2), лимфатического узелка (3), мозговых тяжей (4) поверхностного шейного лимфатического узла 8-месячного плода

быка домашнего (импрегнация азотнокислым серебром)

В отличие от паракортикальных тяжей, относительный объем центральных участков единиц глубокой коры на протяжении всего плодного периода возрастает. В соматических лимфатических узлах их относительный объем достоверно увеличивается, начиная с 6-месячного, а в висцеральных - с 7-месячного возраста. Соотношение относительного объема паракортикальных тяжей и центров единиц глубокой коры в начале плодного периода составляет в поверхностном шейном узле $1 / 14$, а к концу плодного периода только $1 / 2,6$, а в лимфатических узлах тощей кишки - 1/12,0 и 1/2,3 соответственно.

Интерфолликулярная зона в поверхностном шейном лимфатическом узле в начале плодного периода составляет $1 / 7$, а в лимфатическом узле тощей кишки $1 / 6$ относительного объема единиц глубокой коры. На протяжении плодного периода ее относительный объем практически не изменяется и не превышает $10 \%$. Но в связи с тем, что относительный объем единиц глубокой коры постепенно снижается, соотношение объема интерфолликулярной зоны к объему единиц глубокой коры возрастает до 1/2 в соматических узлах и $1 / 4$-в висцеральных.

Лимфатические узелки в лимфоидной паренхиме лимфатических узлов, на протяжении пренатального периода онтогенеза, остаются недостаточно развиты. Их совокупный относительный 
объем в соматических лимфатических узлах достигает $1 \%$ только к 8-месячному возрасту плодов, а к концу пренатального развития не превышает $1,3 \%$. Более развиты лимфатические узелки в висцеральных лимфатических узлах, где до конца 9-месячного возраста их относительный объем достигает более $3 \%$ и среди них выявляются узелки с центрами размножения.

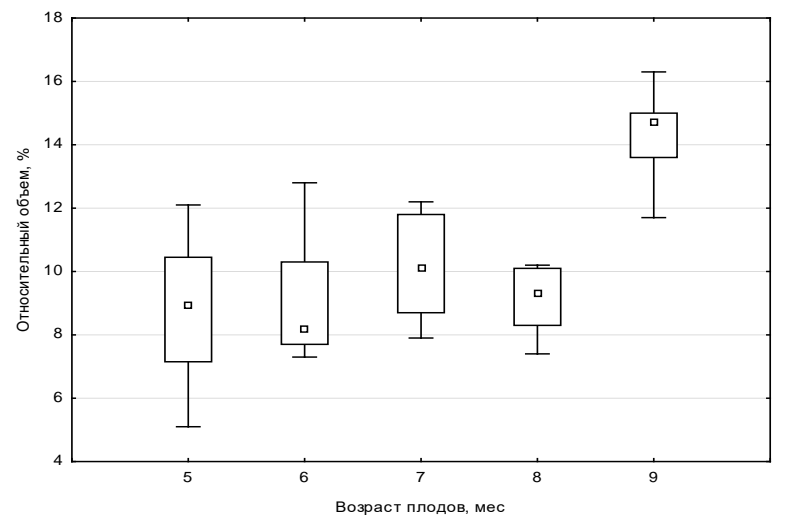

$a$

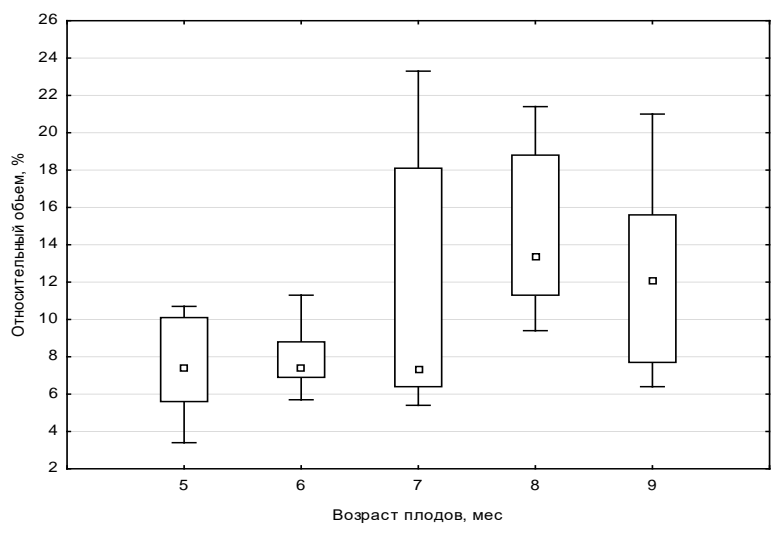

Рис. 7. Динамика относительного объема лимфатических синусов лимфатических узлов быка домашнего на протяжении 5-9 месяцев пренатального периода онтогенеза:

$a$-поверхностный шейный, $\sigma$-лимфоузел тощей кишки

Лимфатические узелки в лимфатических узлах плодов преимущественно располагаются вдоль подкапсулярного синуса на основе интерфолликулярной зоны, но начиная с 8-месячного возраста в некоторых лимфатических узлах тощей кишки они были выявлены на боковых поверхностях единиц глубокой коры, что свидетельствует о возможности их формирования на основе перакортикальных тяжей (рис. 8).

Мозговые тяжи разной конфигурации полностью формируются, начиная с 5-месячного возраста, занимая в соматических и висцеральных узлах около $35 \%$ относительного объема лимфоидной паренхимы. Динамика развития относительного объема мозговых тяжей в соматических лимфатических узлах характеризуется достоверным его уменьшением до 6-месячного возраста, увеличением и стабилизацией показателя с 7-месячного возраста и до конца пренатального развития. В висцеральных лимфатических узлах до 6-го месяца развития плодов отмечен достоверный рост относительного объема мозговых тяжей и резкое его уменьшение до 9-месячного возраста.

Таким образом, к концу плодного периода лимфатические узлы быка домашнего имеют высокую степень структурной дифференциации и представлены достаточно сформированными лимфатическими дольками (компартментами). На протяжении всего пренатального периода онтогенеза лимфатические дольки лимфатических узлов располагаются однослойно вдоль хорошо выраженного подкапсулярного синуса. Между собой лимфатические дольки разделяются капсулярными трабекулами и промежуточными корковими (паракортикальными) синусами. В связи с тем, что капсулярные трабекулы более развиты в соматических узлах, то и степень разделения долек между собой больше выражена в поверхностном шейном узле (рис. 9).

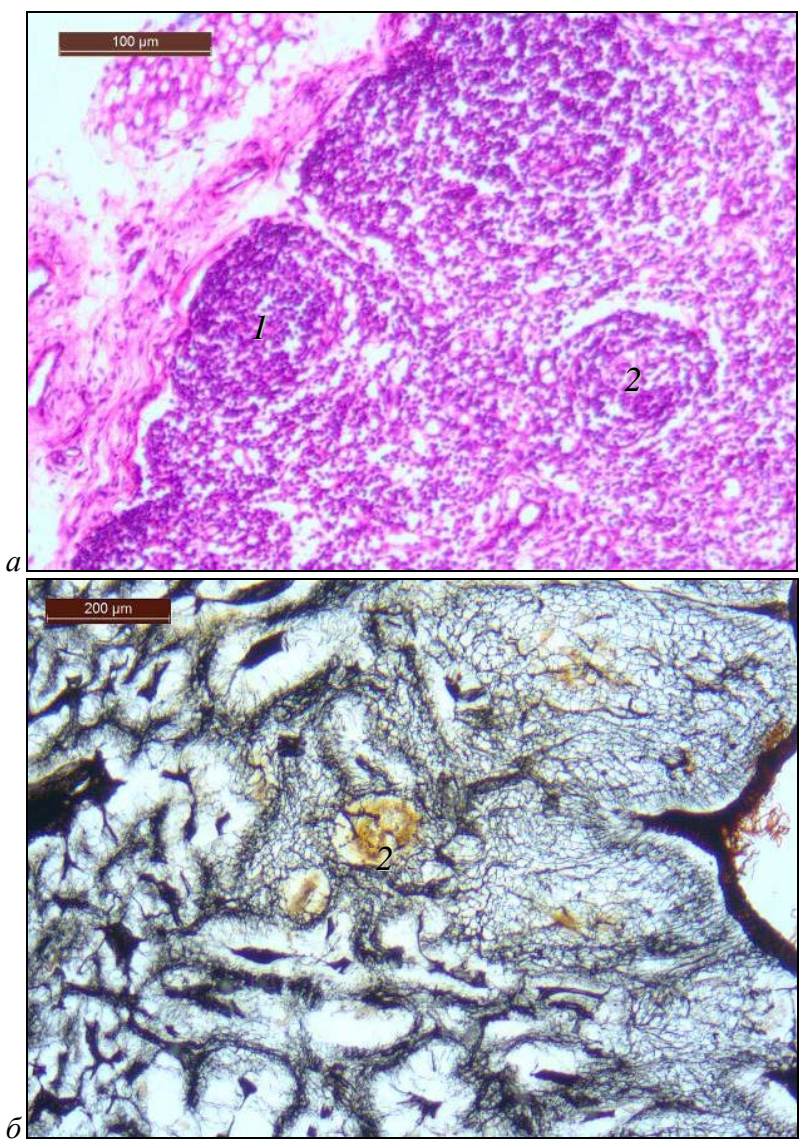

Рис. 8. Лимфатические узелки на основе интерфолликулярной зоны (1) и паракортикальных тяжей (2) в лимфатическом узле тощей кишки: $a$ - гематоксилин и эозин, б-импрегнация азотнокислым серебром

К концу плодного периода онтогенеза практически в каждой лимфатической дольке паренхимы лимфатических узлов плодов выражены все основные структурно-функциональные зоны как транзита лимфоцитов и их клональной пролиферации, так и потенциального накопления плазмоцитов и синтеза антител.

\section{Обсуждение}

Результаты наших исследований свидетельствуют, что у зрелорождающих копытных млекопитающих формирование основных дефинитивных черт строения лимфатических узлов как периферических лимфоидных органов происходит в плодном периоде пренатального онтогенеза поэтапно, с постепенным увеличением степени структурно-функциональной дифференциации лимфоидной паренхимы и, как следствие, формирования комплекса морфологических маркеров иммунокомпетенции.

Дольчатая структура в лимфатических узлах млекопитающих закладывается у предплодов, а основой каждой субъединицы данных органов является отдельная мезенхимальная почка, количество которых в тех или иных узлах детерминировано генетически (Mebius, 2003). В то же время окончательное формирование дольчатой структуры паренхимы с четкой визуализацией данных структур связано с такими факторами как развитие в дольке полного комплекса микроциркуляторного русла, в том числе венул с высоким эндотелием, дифференцировка внутриузловых лимфатических пространств и, как следствие, заселение долек иммунокомпетентными пулами Т- и В-лимфоцитов и включение узлов в общую систему рециркуляции лимфоцитов (De Bruyn \& Cho, 1990; Rjabchikov et al., 2002; Ekman \& Iivanainen, 2009; Benezech et al., 2010; Platt \& Randolph, 2013; Ager, 2017). 
Значительное увеличение в паренхиме лимфатических узлов 3-месячных плодов быка домашнего количества лимфоцитов с концентрацией их вдоль краевого синуса, вероятно, является свидетельством того, что именно в этот период микроциркуляторное русло данных органов приобретает дефинитивные черты строения, а центральные органы иммунной системы продуцируют достаточное для заселения периферических лимфоидных органов количества иммунокомпетентных лимфоцитов (Rjabchikov et al., 2002).

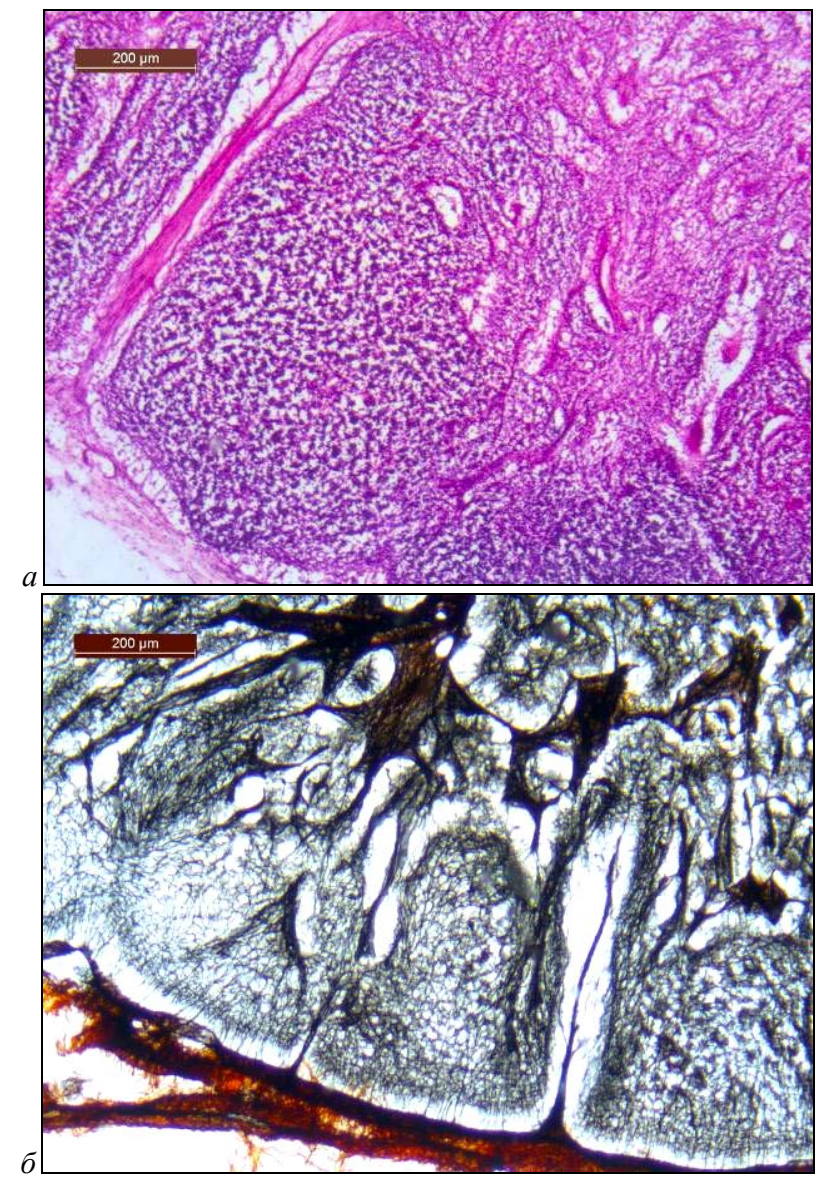

Рис. 9. Лимфатические дольки в паренхиме поверхностного шейного лимфатического узла: $a$ - гематоксилин и эозин, $\sigma$ - импрегнация азотнокислым серебром

Морфологические маркеры наличия в организме плода функции иммунологической реактивности (адаптивного специфического иммунитета) впервые выявляются у 5-месячных плодов. Именно в этот период формируется полнокомпонентное внутриузловое лимфатическое русло, которое включает в себя основной лимфатический коллектор (краевой синус) и ряд их производных (паракортикальные и мозговые синусы).

Зона клональной пролиферации Т- и В-лимфоцитов в лимфатических дольках паренхимы лимфатических узлов 5-месячных плодов развита крайне незначительно на фоне гораздо более существенно развитых зон миграции лимфоцитов (транспортных коридоров), а также мозговых тяжей, которые состоят преимущественно из фибробластических ретикулярных клеток и их волокон (Katakai et al., 2004; Benezech et al., 2010).

Минимальные морфометрические характеристики зон клональной пролиферации лимфоцитов в лимфатических узлах плодов связаны с тем, что у плацентарных млекопитающих антигенный прессинг на органы на ранних этапах онтогенеза является крайне неравномерным, он лавинообразно нарастает непосредственно после рождения, в период постнатальной адаптации и имеет высокие стабильные показатели на дальнейших этапах постнатального развития (Gavrilin et al., 2017a, 2017c).

У плодов млекопитающих, особенно у видов с эпителио- и десмохориальным типом плаценты, в норме абсолютно непрони- цаемой для каких либо относительно крупных молекул, которые могут потенциально иметь антигенные свойства, антигенная «нагрузка» на периферические лимфоидные органы весьма незначительна (Sapin, 2006).

Единственным стимулом для развития антигенреактивных структур в периферических лимфоидных органах у млекопитающих с наиболее совершенным плацентарным барьером считаются эндогенные макромолекуры (эндогенные антигены), концентрация которых в организме плода возрастает пропорционально масштабам формирования соматических систем организма плода (Emelyanenko, 1987; Sapin et al., 1978).

Нами установлено, что в лимфоидных дольках паренхимы плодов быка домашнего на протяжении всего плодного периода масштабы развития (относительный объем) зон клональной пролиферации Т-лимфоцитов значительно преобладает соответствующий показатель В-зависимых зон (лимфатических узелков). Известно также, что у половозрелых и физиологически зрелых млекопитающих два основных типа специфического реагирования относительно уравновешены, а количественные морфометрические характеристики структур, обеспечивающих соответствующие типы иммунологической реактивности, не имеют существенной разницы (Gavrilin et al., 2017c).

Возможно, именно особенности антигенного спектра и свойства аутоантигенов в организме плодов быка домашнего влияют на поляризацию иммунного ответа по Th-1 типу, а цитотоксический иммунный ответ является основным типом специфического реагирования у зрелорождающих млекопитающих с непроницаемым для макромолекул плацентарным барьером (Emelyanenko, 1987).

Характерно также, что морфологические маркеры Th-2 зависимого иммунного ответа больше выражена в висцеральных лимфатических узлах плодов, потенциальным источником антигенов для которых являются как соматические макромолекулы, так и аутоантигены, образующиеся в полости кишечной трубки.

Таким образом, результаты наших исследований свидетельствуют, что автономное развитие плода у быка домашнего и изоляция его от материнских антигенов и, соответственно, антигенов внешней среды не являются преградой для дифференцировки паренхимы лимфатических узлов на лимфоидные дольки с отдельными структурно-функциональными зонами, которые являются морфологическими маркерами функции адаптивного специфического иммунитета. В то же время лимфоидные дольки лимфатических узлов на момент рождения плодов имеют ряд «эмбриональных» черт (относительная стабильность объема всех функциональных зон, минимальная степень развития зон клональной пролиферации Т- и В-лимфоцитов, что обусловлено условиями их существования.

Эмбриональная лимфоидная долька имеет характерную однополярную гистоархитектонику и специфическую слоисто-дискретную структуру без мозаичности, присущей соответствующим образованиям паренхимы узлов в постнатальном онтогенезе (Gavrilin et al., 2017a). Слоистым компонетом в лимфоидной дольке лимфатических узлов плодов являются интрафолликулярная зона (корковое плато), а также зона мозговых тяжей, а дискретной единицы глубокой коры с выраженным сферообразным центром (зона клональной пролиферации Т-лимфоцитов). Лимфатические узелки, которые в лимфоидной дольке «постэмбриональных» лимфатических узлов расположены диффузно от интерфолликулярной зоны до зоны мозговых тяжей, у плодов концентрируются преимущественно вдоль краевого синуса в интрафолликулярной зоне и, как исключение, отдельные из них могут развиваться в начальных участках паракортикальных тяжей в лимфатических узлах тощей кишки. Возможно, это является следствием весьма умеренных иммунореактивных свойств внутриутробных аутоантигенов (Sapin, 2006).

\section{Выводы}

В лимфатических узлах зрелорождающих копытных млекопитающих (быка домашнего) с лимфатическими коллекторами 
простого типа морфологические признаки структурно-функциональной дифференциации и специализации паренхимы впервые выявляются у 3-месячных плодов, а степень выраженности структурной гетерогенности лимфоидной ткани до конца плодного периода постоянно усиливается. В развитии лимфоидной паренхимы лимфатических узлов у плодов выделяется ряд последовательных этапов: формирование лимфоидного матрикса вдоль краевого синуса узлов без выраженной дольчатости (3-4-месячные плоды); обособление лимфоидных долек в целом и формирование их основных функциональных зон (транзита лимфоцитов, клональной пролиферации Т- и В-лимфоцитов, аккумуляции плазматических клеток и антителообразования) (5-месячные плоды); развитие компонентов лимфоидных долек преимущественно за счет увеличения объема зон транзита лимфоцитов и клональной пролиферации Т- и В-лимфоцитов.

В лимфоидных дольках лимфатических узлов быка домашнего с момента формирования данных органов до конца плодного периода наиболее развитыми, с максимальным относительным объемом, являются зоны транзита лимфоцитов (интерфолликулярная зона и паракортикальные тяжи), а также зона потенциальной аккумуляции лимфоцитов и антителообразования (мозговые тяжи). Среди зон клональной пролиферации лимфоцитов на всех этапах развития долек с момента их обособления преобладают Т-зависимые зоны, относительный объем которых в 5,0-7,5 раза превышает соответствующие показатели В-зависимых зон. Пренатальное развитие компартментов у плодов быка домашнего характеризуется постепенным увеличением, от незначительного до умеренного, относительного объема зон клональной пролиферации Т- и В-лимфоцитов. При этом относительный объем зон транзита лимфоцитов, а также аккумуляции плазматических клеток имеет тенденцию к уменьшению.

Гистоархитектоника лимфоидных долек на протяжении всего плодного периода существенно не изменяется и характеризуется однослойностью расположения компартментов, их выраженной полярной структурой, формированием лимфатических узелков преимущественно вдоль основного лимфатического коллектора (краевого синуса), за исключением висцеральных узлов брюшной полости, где лимфатические узлы образуются на основе паракортикальных тяжей.

Дальнейшие исследования особенностей пренатального морфогенеза компартментов лимфатических узлов быка домашнего будут направлены на выяснение закономерностей их цитогенеза с выявлением основных маркеров дифференцировки и клональной пролиферации лимфоцитов.

\section{References}

Aagaard, K., Ma, J., Antony, K. M., Ganu, R., Petrosino, J., \& Versalovic, J. (2014). The placenta harbors a unique microbiome. Science Translational Medicine, 6, 237ra65-237ra65.

Ager, A. (2017). High endothelial venules and other blood vessels: Critical regulators of lymphoid organ development and function. Frontiers in Immunology, 8(3), 1-16.

Avtandilov, G. G. (1990). Meditsinskaya morfometrya [Medical morphometry]. Medicine, Moscow (in Russian).

Bélisle, C., \& Sainte-Marie, G. (1981). Tridimensional study of the deep cortex of the rat lymph node. III. Morphology of the deep cortex units. The Anatomical Record, 199(2), 213-226.

Benezech, C., White, A., Mader, E., Serre, K., Parnell, S., Pfeffer, K., Ware, C. F., Anderson, G., \& Caamano, J. H. (2010). Ontogeny of stromal organizer cells during lymph node development. The Journal of Immunology, 184(8), 4521-4530.

Butler, J., Sawtell, A., Jarrett, S., Cosgrove, J., Leigh, R., Timmis, J., \& Coles, M. (2016). Imaging immunity in lymph nodes: Past, present and future. Advances in Experimental Medicine and Biology, 915, 329-346.

Capece, T., \& Kim, M. (2016). The role of lymphatic niches in T cell differentiation. Molecules and Cells, 39(7), 515-523.

Chuchkova, N. N., Smetanina, M. V., Kormilina, N. V., \& Komissarov, V. B. (2016). Morfogenez limfaticheskih uzlov v uslovijah hronicheskogo systemnogo vospalenija [The morphogenesis of lymph nodes in conditions of chronic systemic inflammation]. Morfologija, 149(3), 230-231 (in Russian).
De Bruyn, P. P. H., \& Cho, Y. (1990). Structure and function of high endothelial postcapillary venules in lymphocyte circulation. In: Grundmann, E., \& Vollmer, E. (Eds.). Reaction patterns of the lymph node. Current Topics in Pathology, 84(1). Springer, Berlin, Heidelberg. pp. 85-101.

Ekman, A., \& Iivanainen, A. (2009). Generation of B cells in bovine fetuses. Veterinary Immunology and Immunopathology, 128(1-3), 268.

Emelyanenko, P. A. (1987). Immunologia zhivotnych v period vnytriutrobnogo razvitia [Immunology of animals in the period of intrauterine development]. Agropromizdat, Moscow (in Russian).

Gavrilin, P. N. (1999). Modificatsiya sposoba impregnatsii serebrom po Futy gistotopogramm organov krovetvoreniya, izgotovlennyih na microtomekriostate [Modification of the silver impregnation method according to Fut histotopograms of hemopoietic organs made on a microtome cryostat]. Vestnik Morphologii, 5(1), 106-108 (in Russian).

Gavrilin, P. N., Gavrilina, O. G., \& Kravtsova, M. V. (2017a). The compartments of the parenchyma of the lymph nodes in the newborn bull calves of domestic cattle (Bos taurus). Regulatory Mechanisms in Biosystems, 8(2), 169-178.

Gavrilin, P. N., Gavrilina, O. G., Brygadyrenko, V. V., \& Rahmoun, D. E. (2017b). Structural and functional units of parenchyma of lymph nodes of dromedaries (Camelus dromedarius). Regulatory Mechanisms in Biosystems, 8(3), 323-332.

Gavrilin, P., Gavrilina, E., \& Evert, V. (2017c). Histoarchitectonics of the parenchyma of lymph nodes of mammals with different structure of intranodal lymphatic channel. Ukrainian Journal of Ecology, 7(3), 96-107.

Gavrilin, P. N., Masjuk, M. O., \& Tishkina, N. N. (2014). Osoblivosti makrosko pichnoi strukturi limfatichnih vuzliv svini sviyskoi [Features of macroscopic structure of lymph nodes of the domestic pig]. Science and Technology Bulletin of SRC for Biosafety and Environmental Control of AIC, 2(1), 32-37 (in Ukrainian).

Gretz, J. E., Anderson, C. C., \& Shaw, S. (1997). Cords, channels, corridors and conduits, critical architectural facilitating cell interactions in the lymph node cortex. Immunological Reviews, 156, 11-24.

Grigor'ev, V. S., \& Moljanova, G. V. (2009). Organogenez central'nyh i perifericheskih organov immunnoj sistemy u sel'skohozjajstvennyh zhivotnyh [Organogenesis of central and peripheral bodies of the immune system in agricultural animals]. RIC SGSHA, Samara (in Russian).

Hlystova, Z. S. (1987). Stanovlenie sistemy immunogeneza ploda cheloveka [Formation of the system of human fetal immunogenesis]. Medicine, Moscow (in Russian).

Houston, S. A., Cerovic, V., Thomson, C., Brewer, J., Mowat, A. M., \& Milling, S. (2016). The lymph nodes draining the small intestine and colon are anatomically separate and immunologically distinct. Mucosal Immunology. 9(2), $468-478$.

Hoshi, N., Hashimoto, Y., Kitagawa, H., Kon, Y., \& Kudo, N. (1986). Histological and immunohistochemical studies on the architecture of lymph nodes in pig. Japan Journal Veterinary Science, 48(6), 1097-1107.

Ikomi, F., Kawai, Y., \& Ohhashi, T. (2012). Recent advance in lymph dynamic analysis in lymphatics and lymph nodes. Annals of Vascular Diseases, 5(3), 258-268.

Iwasaki, R., Mori, T., Ito, Y., Kawabe, M., Murakmi, M., \& Maruo, K. (2016). Computed tomographic evaluation of presumptively normal canine sternal lymph nodes. Journal of the American Animal Hospital Association, 52(6), 371-377.

Jeklova, E., Leva, L., \& Faldyna, M. (2007). Lymphoid organ development in rabbits: Major lymphocyte subsets. Developmental and Comparative Immunology, 31(6), 632-644.

Jia, L., Xie, Z., Zheng, J., Liu, L., He, Y., Liu, F., \& He, Y. (2012). Morphological studies of lymphatic labyrinths in the rat mesenteric lymph node. The Anatomical Record, 295, 1291-1301.

Kaldjian, E. P., Gretz, J. E., Anderson, A. O., Shi, Y., \& Shaw, S. (2001). Spatial and molecular organization of lymph node T cell cortex: A labyrinthine cavity bounded by an epithelium-like monolayer of fibroblastic reticular cells anchored to basement membrane-like extracellular matrix. International Immunology, 13(10), 1243-1253.

Katakai, T. (2004). A novel reticular stromal structure in lymph node cortex: An immuno-platform for interactions among dendritic cells, T cells and B cells. International Immunology, 16(8), 1133-1142.

Katakai, T., Hara, T., Sugai, M., Gonda, H., \& Shimizu, A. (2004). Lymph node fibroblastic reticular cells construct the stromal reticulum via contact with lymphocytes. The Journal of Experimental Medicine, 200(6), 783-795.

Kelly, R. H. (1975). Functional anatomy of lymph nodes. International Archives of Allergy and Immunology, 48(6), 836-849.

Konenkov, V. I., Shkyrat, G. A., \& Kolesnikov, A. P. (2008). Limfaticheksij uzel: Morfofunkcional'naja harakteristika i mezhkletochnaja kooperacija [Lymph node: Morphofunctional characteristic and intercellular cooperation]. Vestnik Limfologii, 4, 35-43 (in Russian). 
Kowala, M. C., \& Schoefi, G. I. (1986). The popliteal lymph node of the mouse: Internal architecture, vascular distribution and lymphatic supply. Journal of Anatomy, 148(1), 25-46.

Lipscomb, M. F., \& Masten, B. J. (2002). Dendritic cells: Immune regulators in health and disease. Physiological Reviews, 82(1), 97-130.

Margaris, K. N., \& Black, R. A. (2012). Modelling the lymphatic system: Challenges and opportunities. Journal of the Royal Society Interface, 9(69), 601-612.

Mebius, R. E. (2003). Erratum: Organogenesis of lymphoid tissues. Nature Reviews Immunology, 3(4), 292-303.

Nicander, L., Nafstad, P., Landsverk, T., \& Engebretsen, R. H. (1991). A study of modified lymphatics in the deep cortex of ruminant lymph nodes. Journal of Anatomy, 178, 203-212.

Nishikawa, S.-I., Honda, K., Vieira, P., \& Yoshida, H. (2003). Organogenesis of peripheral lymphoid organs. Immunological Reviews, 195(1), 72-80.

Nurken, M., \& Marzhan, M. (2016). The movement of lymph in the system of lymph node-lymph vessel and its regulation. Australasian Medical Journal, $9(10)$.

Ohtani, O., \& Ohtani, Y. (2008). Structure and function of rat lymph nodes. Archives of Histology and Cytology, 71(2), 69-76.

Olson, M. R., McDermott, D. S., \& Varga, S. M. (2012). The initial draining lymph node primes the bulk of the CD8 T cell response and influences memory T cell trafficking after a systemic viral infection. PLOS Pathogens, 8(12), 1-15.

Palm, A.-K. E., Friedrich, H. C., \& Kleinau, S. (2016). Nodal marginal zone B cells in mice: A novel subset with dormant self-reactivity. Scientific Reports, 6(1).

Parker, G. A., \& Makori, N. (2017). Development of immune system organs. Reference Module in Biomedical Sciences, 11, 49-73.

Platt, A. M., \& Randolph, G. J. (2013). Dendritic cell migration through the lymphatic vasculature to lymph nodes. Advances in Immunology, 120, 51-68.

Randall, T. D., Carragher, D. M., \& Rangel-Moreno, J. (2008). Development of secondary lymphoid organs. Annual Review of Immunology, 26(1), 627-650.

Rjabchikov, O. P., Kalinina, I. I., Shmeleva, S. P., Hlystova, Z. S., Minina, T. A., \& Rabotnikova, E. L. (2002). Karta zaselenija organov immunnoj sistemy jembriona i ploda cheloveka T- i B-limfocitami i nachalo jendokrinnoj funkcii timusa [Map of the population of the organs of the immune system of the embryo and fetus of human T- and B-lymphocytes and the beginning of the endocrine function of the thymus]. Immunologija, 2, 80-82 (in Russian).

Ruddle, N. H. (2016). High endothelial venules and lymphatic vessels in tertiary lymphoid organs: Characteristics, functions, and regulation. Frontiers in Immunology, 9(7), 1-7.
Rouse, R. V., Reichert, R. A., Gallatin, W. M., Weissman, I. L., \& Bucher, E. C. (1984). Localization of lymphocyte subpopulation in peripheral lymphoid organs: Directed lymphocyte migration and segregation into specific microenvironments. American Journal of Anatomy, 170, 391-405.

Sainte-Marie, G. (2010). The lymph node revisited: Development, morphology, functioning, and role in triggering primary immune responses. The Anatomical Record, 293(2), 32-37.

Sapin, M. R., Jurina, N. A., \& Etingen, L. (1978). Limfaticheskij uzel [Lymph node] Medicine, Moscow (in Russian).

Sapin, M. R. (2006). Osobennosti imunnogo otveta pri razlichnych vnechnich vozdeistviyah [Features of the immune response under various external influences]. Morphology, 129(4), 109-110 (in Russian).

Sinkora, J., Rehakova, Z., Sinkora, M., Cukrowska, B., \& Tlaskalova-Hogenova, H. (2002). Early development of immune system in pigs. Veterinary Immunology and Immunopathology, 87(3-4), 301-306.

Šinkora, M., \& Butler, J. E. (2009). The ontogeny of the porcine immune system. Developmental and Comparative Immunology, 33(3), 273-283.

Sixt, M., Kanazawa, N., Selg, M., Samson, T., Roos, G., Reinhardt, D. P., Pabst, R., Lutz, M. B., \& Sorokin, L. (2005). The conduit system transports soluble antigens from the afferent lymph to resident dendritic cells in the T cell area of the lymph node. Immunity, 22(1), 19-29.

Sminia, T., Van Rees, E. P., Döpp, E. A., \& Dijkstra, C. D. (1986). Ontogeny of the popliteal lymph node in the rat. Developmental and Comparative Immunology, 10(1), 119.

Studencov, A. P., Shipilov, V. S., Nikitin, V. J., Miroljubov, M. G., Subbotina, L. G., Preobrazhenskij, O. N., \& Hromcov, V. V. (1999). Veterinarnoe akusherstvo, ginekologija i biotehnika razmnozhenija [Veterinary obstetrics, gynecology and biotechnics of reproduction]. Kolos, Moscow (in Russian).

Von Andrian, U. H., \& Mempel, T. R. (2003). Homing and cellular traffic in lymph nodes. Nature Reviews Immunology, 3(11), 867-878.

Vyrenkov, Y. E., Shishlo, V. K., Antropova, J. G., \& Ryzhova, A. V. (1995). Sovremennye dannye o strukturno-funkcional'noj organizacii limfaticheskogo uzla [Modem data on the structural and functional organization of the lymph node]. Morphology, 103(3), 34-40 (in Russian).

Willard-Mack, C. L. (2006). Normal structure, function, and histology of lymph nodes. Toxicologic Pathology, 34(5), 409-424.

Zelenevsky, N. V. (2013). Mezhdunarodnaja veterinamaja anatomicheskaja nomenklatura na latinskom i russkom jazykah. Nomina Anatomica Veterinaria [International veterinary anatomical nomenclature in Latin and Russian. Nomina Anatomica Veterinaria]. Mir, Sankt-Peterburg (in Russian). 